Jean Christophe Marie Richard Robert M. Kacmarek

\section{ICU mechanical ventilators, technological advances vs. user friendliness: the right picture is worth a thousand numbers}

Received: 6 July 2009

Accepted: 6 July 2009

Published online: 29 July 2009

(C) Springer-Verlag 2009

This editorial refers to the article available at: doi:10.1007/s00134-009-1580-7.

\section{J. C. M. Richard}

Medical Intensive Care Unit, UPRES EA 3830,

Rouen University Hospital, Paris, France

R. M. Kacmarek (®)

Respiratory Care, Massachusetts General Hospital,

55 Fruit St, Boston, MA 02114, USA

e-mail: rkacmarek@partners.org

Tel.: +1-617-7244490

Fax: +1-617-7244495

Over the last two decades, technological developments have lead to significant improvements of the performances by ICU ventilators [1-4]. At the same time, the presentation of data and the interface of the ventilator with the clinician have also changed dramatically. In the 1980s all ventilators were mechanical in their operation [5]. All parameters were controlled by simple, and in most cases, easily accessible knobs that the clinician simply turned to the desired setting or mode. Today's ICU ventilators are composed primarily of a series of microprocessors controlling a gas delivery platform [1-5]. As a result, the capabilities of today's ICU ventilators are markedly greater than previous generations of ventilators. New modes are available, closed loop control is increasingly being used, monitoring capabilities are expanded and the user interface is different. Indeed, almost all of the newest generation of ICU ventilators incorporate a computer screen as the basis of their user interface [5]. Many have layers of menus that the user must navigate in order to make changes in ventilator settings, and many require multiple steps to make a simple change in any ventilator parameter $[4,5]$. All of this has made the user interface more and more complex for the untrained individual to understand and master. As a consequence, decision making and safety may be a challenge in routine practice. It has been emphasized that human error is responsible of the majority of medical accidents [6] and that most of these accidents are considered avoidable [7]. In this context, the development of user-machine interfaces specifically designed to facilitate cognitive processes may increase the ease of care giver interactions and reduce the number of accidents.

In this issue of ICM, Vignaux et al. [8] report on the results of a bench evaluation of the user-friendliness of seven ICU ventilators by asking ten physicians with ICU ventilator experience, but who are unfamiliar with the tested ventilators, to perform eight predefined ventilator maneuvers on the bench. Tested ventilators all belonged to the recent generation of ICU ventilators with user interfaces based on varying screen technologies. The data reported in this paper outlines the variability in operational design and the ergonomic shortcomings of these ventilators. Although significant differences among ventilators were reported, the clinical relevance of the time differences to accomplish various tasks remains questionable. In this regard, it would have been interesting to correlate the results observed in experimental conditions with those observed in actual clinical practice. Nevertheless, considering that ventilator performance improvement observed over the last two decades may have reached a ceiling [3], the conclusions of Vignaux et al. [8] regarding the need to improve user friendliness makes perfect sense. Similar conclusions have been proposed by a number of other groups also evaluating the operational friendliness of the current generation mechanical ventilators $[9,10]$. 
Hence manufactures are left with a challenge to insure user friendliness but also to maintain patient safety. This is a challenge but one that is not insurmountable. Standardization of terminology across manufacturers would help immensely with the confusion introduced by manufacturers' unique language in reference to modes or adjuncts. Incorporating help screens that provide operational instruction would also reduce confusion. Presenting information instead of data on ventilator performance or changes in a patient's condition is a necessity. Most current ventilators present $20-30$ or more specific variables about the ventilator or patient, but do not provide any decision support regarding the significance of these variables. Eye tracking technology, based on the pioneering work by Cole and Stewart [11], would help in identifying clinical problems. Specifically, the incorporation of graphical displays designed to facilitate the recognition of simple clinical scenarios (i.e., tube obstruction, airway pressure increase, gas trapping, etc.) would help immensely. The benefit of a picture-graphical pulmonary display has been recently evaluated in a bench study. Nineteen volunteers tested their ability to diagnose and treat four respiratory scenarios mimicked in a lung model [12]. Volunteers detected and treated obstructed endotracheal tubes and intrinsic PEEP problems significantly faster with graphical rather than conventional displays suggesting that a cognitive based graphical display may serve a useful adjunct to traditional displays in identifying adverse respiratory events.

From the patient safety perspective, manufacturers are required to insure that their devices are safe for patient use and that inadvertent adjustment of the device, possibly leading to patient harm, is reasonably avoidable. Here is where the controversy exists. What level of expertise should an individual have before they proceed to make an adjustment on a mechanical ventilator? Vignaux et al. [8] imply that ventilators should be designed so that any physician intern, resident, fellow or attending physician should be able to walk up to the ventilator and make changes in its operation even if they were not familiar with the device. A recent Joint Commission [13] sentinel event alert reported on preventable deaths and injuries related to mechanical ventilation. Their root cause analysis indicated that in $87 \%$ of the instances part of the cause of death or injury was inadequate orientation/ training of clinicians operating the mechanical ventilator. Regardless of how user-friendly a mechanical ventilator, we believe that no one should be operating the ventilator even in emergency situations unless they have demonstrated competency in the operation of the ventilator. In an emergency there is always a manual ventilator available until appropriately trained personnel arrive.

Mechanical ventilator user friendliness is a necessity. As the capabilities and complexities of mechanical ventilators continue to increase we also join the group of clinicians asking for a more user friendly and ergonomically designed interface. We on the other hand insist that those operating any mechanical ventilator regardless of their status should have demonstrated competency in its operation before independently manipulating the mechanical ventilator!

\section{References}

1. Richard JC, Carlucci A, Breton L, Langlais N, Jaber S, Maggiore S, Fougère S, Harf A, Brochard L (2002) Bench testing of pressure support ventilation with three different generations of ventilators. Intensive Care Med 28:1049-1057

2. Tassaux D, Michotte JB, Gainnier M, Gratadour P, Fonseca S, Jolliet P (2004) Expiratory trigger setting in pressure support ventilation: from mathematical model to bedside. Crit Care Med 32:1844-1850

3. Thille AW, Lyazidi A, Richard JC, Galia F, Brochard L (2009) A bench study of intensive-care-unit ventilators: new versus old and turbine-based versus compressed gas-based ventilators. Intensive Care Med 8 April 2009, Epub ahead of print

4. Marchese AD, Chipman D, de la Oliva P, Kacmarek RM (2009) Adult ICU ventilators to provide neonatal ventilation: a lung simulator study. Intensive Care Med 35:631-638
5. Kacmarek RM, Chipman D (2006) Basic principles of ventilator machinery. In: Tobin MJ (ed) Principles and practice of mechanical ventilation, 2nd edn. McGraw-Hill Publishers, New York, pp 53-97

6. Kohn L, Corrigan J, Donaldson M (2000) To err is human: building a safer health system. National Academy Press, Washington, DC

7. Bracco D, Favre JB, Bissonnette B, Wasserfallen JB, Revelly JP, Ravussin P, Chioléro R (2001) Human errors in a multidisciplinary intensive care unit: a 1 -year prospective study. Intensive Care Med 27:137-145

8. Vignaux L, Tassaux D, Philippe J (2009) Evaluation of the userfriendliness of 7 new generation ICU ventilators. Intensive Care Med 35
9. Gonzalez-Bermejo J, Laplanche V, Husseini FE, Duguet A, Derenne JP, Similowski T (2006) Evaluation of the user-friendliness of 11 home mechanical ventilators. Eur Respir J 27:1236-1243

10. Uzawa Y, Yamada Y, Suzukawa M (2008) Evaluation of the user interface simplicity in the modern generation of mechanical ventilators. Respir Care 53:329-337

11. Cole WG, Stewart JG (1994) Human performance evaluation of a metaphor graphic display for respiratory data. Methods inf med 33:390-396

12. Wachter SB, Johnson K, Albert R, Syroid N, Drews F, Westenskow D (2006) The evaluation of a pulmonary display to detect adverse respiratory events using high resolution human simulator. J Am Med Inform Assoc 13:635-642

13. Joint Commision (2002) Preventing ventilator-related deaths and injuries. Sentinel Event Alert 25, 26 February 2002 